\title{
Museus de arte universitários: vocações, especificidades e potencialidades
}

\author{
Fernanda Carvalho de Albuquerque ${ }^{1}$, Marília de Oliveira Frozza ${ }^{2}$
}

\section{Resumo:}

Este artigo parte do levantamento sobre as definições, funções e origens dos museus de arte universitários para estabelecer uma reflexão sobre os papeis e o lugar dessas instituições na universidade. A vocação dos museus para atuar enquanto plataformas de ensino, pesquisa e extensão é o ponto de partida para reconhecer particularidades e indagar potencialidades.

Palavras-chave: museu de arte; universidade; ensino; pesquisa; extensão.

\section{College art museums: vocations, specificities and potentialities}

In order to reflect on the roles college art museums play and the places they belong to in the universities, this article reviews definitions, functions and origins of these institutions. The vocation of college museums to act as platforms for teaching, research and extension is the starting point for the recognition of particularities and the exploration of potentialities of this kind of institution.

Keywords: art museum; university; teaching; research; extension.

\footnotetext{
${ }^{1}$ Fernanda Albuquerque é curadora e professora do Curso de Museologia, da Especialização em Práticas Curatoriais e do Programa de Pós-Graduação em Museologia e Patrimônio, todos eles da UFRGS. É Doutora em Artes Visuais pela UFRGS (2015), com estágio na University of the Arts London (UAL). Foi Curadora Assistente da 8a Bienal do Mercosul (2011) e Curadora de Artes Visuais do Centro Cultural São Paulo (2008-2010). Já desenvolveu projetos para instituições como Instituto Tomie Ohtake, Bienal de São Paulo, Goethe Institut Porto Alegre, Santander Cultural, Galería Gabriela Mistral, Museu Murillo La Greca e Centro Universitário Maria Antonia, dentre outros.

${ }^{2}$ Bacharela em História da Arte (IA/UFRGS) e graduanda em Museologia (FABICO/UFRGS). Atuou como bolsista de Iniciação Científica (PIBIC CNPq-UFRGS/2017, BIC UFRGS/2017-2018) no projeto de pesquisa "Museus de arte universitários e seus programas curatoriais: ensino, pesquisa e extensão", com orientação da Profa. Dra. Fernanda Albuquerque. Atualmente realiza estágio no Setor de Acervo da Fundação Vera Chaves Barcellos, em Viamão-RS.
} 
Os museus de arte universitários apresentam especificidades em relação a outras instituições museais de arte? Que particularidades são essas? E quais as suas potencialidades? Essas perguntas estão na base do presente artigo. Nessa linha, indagamos ainda em que medida os museus de arte universitários podem ser considerados museus-escola ou museus-laboratório. Tanto no sentido de atuarem como plataformas de produção e compartilhamento de conhecimentos valiosos aos processos de ensino-aprendizagem (em arte, museologia e áreas afins) e fundamentais às abordagens em relação aos seus acervos, programas curatoriais, contextos e públicos; quanto no sentido de serem instituições em constante processo de repensar a si mesmas e de reinventar-se, testando novas ferramentas, práticas, processos e formatos para as funções que desempenham, a saber, colecionar, preservar, pesquisar, interpretar e expor (Poulot, 2013: 22).

Este texto apresenta, assim, uma síntese dos estudos e reflexões desenvolvidos sobre os museus de arte universitários, sobretudo no que diz respeito às suas definições, funções e origens, bem como seus processos de formação, seja no Brasil, seja em outras partes do mundo, para estabelecer uma reflexão sobre os papeis e o lugar que tais instituições ocupam nas universidades, de modo a compreender as vocações, especificidades e potencialidades dessa tipologia de museu. [1]

\section{Definições, funções e origens dos museus de arte universitários}

Partimos da definição de museu universitário trazida pela pesquisadora Adriana Mortara Almeida, segundo a qual uma coleção ou um museu universitário se caracteriza por estar parcial ou totalmente sob a responsabilidade de uma universidade, da salvaguarda do acervo aos recursos humanos e espaço físico (Almeida, 2001).

De acordo com Almeida (2001):

[...] as funções de um museu universitário estão ligadas à história da universidade, da formação da coleção e também da região em que se localiza. Esses fatores, aliados às políticas de ensino, pesquisa e extensão das universidades, são fundamentais para a construção do perfil do museu. (Almeida, 2001: 27) 
Ela enfatiza, portanto, a condição primeira de um museu desse tipo, sua situação jurídicoadministrativa. Mas o que significa para uma instituição museal estar sob a responsabilidade de uma universidade? Quais as relações possíveis entre esses diferentes universos, o de um museu de arte e o de uma universidade? E quais as potencialidades dessa relação?

O professor e pesquisador Ulpiano Bezerra de Menezes apresenta algumas possibilidades de resposta a essas perguntas, atentando para as funções primeiras de um museu universitário nesse caso, não especificamente um museu de arte universitário.

O museu universitário propriamente dito teria que integrar solidariamente as funções científico-documentais, educacionais e culturais da universidade com a marca da ação museal - e não apenas existir como museu que se vincula administrativamente a uma universidade. (Menezes, 2010: 27)

Em outras palavras, ela aponta para o fato de que a especificidade do museu universitário não está na sua administração, mas na articulação de suas funções às funções da própria universidade: científico-documentais, educacionais e culturais. Dito de outro modo, funções relativas à pesquisa, ao ensino e à extensão, tripé da vida universitária no Brasil. Resta saber como essa articulação de funções pode se dar.

Outro caminho para pensar o que diferencia um museu de arte universitário de outros museus é o público a quem ele serve, isto é, a comunidade universitária - muito embora um museu desse tipo possa atrair e servir a vários outros públicos também. Nesse sentido, cabe indagar: o que significa um museu atender prioritariamente a comunidade universitária? Quais as particularidades de sua atuação nesse sentido? Como se aproximar e engajar tal público? Que tipo de programas ele pode desenvolver?

Até aqui temos que é próprio do museu universitário estar sob a responsabilidade de uma universidade, integrar suas funções às funções da universidade em questão e ter como público primeiro a comunidade universitária. Ficam, no entanto, questões relativas aos significados dessas particularidades, como já apontamos. E permanecem outras questões: quais as 
particularidades do museu de arte universitário no que diz respeito à sua relação com outros públicos, para além da comunidade universitária, especialmente o meio artístico e cultural?

Se tomarmos por base as funções que os museus normalmente desempenham - colecionar, conservar, pesquisar, interpretar e expor -, poderíamos nos perguntar, ainda, qual a especificidade de levar a cabo tais funções em um meio universitário, isto é, em um museu que integra uma universidade. Não seria a indagação dessas próprias funções uma particularidade dos museus de arte universitários? Um estudo de 1942 do pesquisador Laurence Vail Coleman sugere que as salas de exposição, em um museu universitário, deveriam ser projetadas como locais de trabalho. Em outras palavras, como locais de estudo e pesquisa, em que as disposições de obras e as relações possíveis entre elas - elas as obras e também suas diferentes disposições - não se dariam de modo afirmativo, mas como perguntas, indagações, possibilidades. Pois não faria sentido estender tal entendimento às outras funções do museu, para além da função de expor?

As origens dos museus universitários remontam à Biblioteca de Alexandria, criada em cerca de 280 a.C., a qual tinha características que hoje são identificadas tanto com uma universidade quanto com um museu, pois o mouseion de Alexandria possuía coleções de objetos e livros, laboratórios, jardim botânico e zoológico à disposição dos pensadores da época. A abertura do Ashmolean Museum da Universidade de Oxford na Grã-Bretanha, em 1683, é recorrentemente apontada como um marco do início dos museus abertos ao público, assim como é o primeiro museu universitário da Europa.

Segundo a pesquisadora Adriana Mortara Almeida:

Os primeiros museus universitários formaram-se a partir da doação de grandes coleções particulares às universidades. A atitude do colecionador elou seus herdeiros, de passar a salvaguarda de uma coleção à universidade, pressupunha que a instituição era digna, adequada e competente para exercer essa função. (Almeida, 2001: 13)

Quanto aos processos de formação dos museus universitários, é possível identificar as seguintes situações: 
[...] via aquisição de objetos ou coleções de particulares por doação ou compra, via transferência de um museu já formado para responsabilidade da universidade, via coleta e pesquisa de campo ou então pela combinação desses processos. (Almeida, 2001: 13).

Nos casos de aquisição de objetos ou coleções, assim como de transferência para a universidade, pode ocorrer dessas coleções não serem utilizadas para o ensino e a pesquisa, sobressaindo-se o valor cultural desses acervos para a comunidade acadêmica. Já a formação de um museu universitário através da coleta e pesquisa de campo está geralmente relacionada às coleções de ciências.

No caso dos museus de arte universitários, a pesquisadora Adriana Mortara Almeida observa que muitos foram criados antes da existência de cursos de artes ou de história da arte nas universidades, pois em meados do século XIX, coleções privadas de arte foram doadas às universidades, sendo tomadas como "fonte de enriquecimento cultural do campus e da vida universitária" (Almeida, 2001: 20). São raros os casos de museus de arte universitários que formaram suas coleções a partir de e voltadas para o ensino e a pesquisa.

No Brasil, os museus universitários surgem tanto no momento da criação das universidades quanto são posteriormente vinculados a essas instituições de ensino superior, sendo que a maioria dos museus universitários brasileiros foi instituída a partir da década de 1950.

Ao refletirmos sobre as relações estabelecidas entre o museu universitário, especialmente os de arte, e a universidade, por meio do ensino, da pesquisa e da extensão, observamos que essas relações se definem muito a partir de como o museu está vinculado à universidade e do valor $\mathrm{e}$ lugar que a comunidade acadêmica lhe confere: seja em termos do valor cultural e artístico de seu acervo para a universidade e comunidade de modo mais amplo, valor este muitas vezes já consagrado pela sociedade; seja em termos dos seus usos mais objetivos para o ensino e para a pesquisa em âmbito acadêmico.

\section{Dos papeis e do lugar dos museus de arte universitários nas universidades}


O debate e as considerações sobre os museus de arte universitários nos Estados Unidos, promovidos pelos estudos da pesquisadora Corrine Glesne (2012) e pelas contribuições advindas de entrevistas com diretores de museus de arte universitários e especialistas no tema realizadas para a publicação Campus Art Museums in the 21st Century: A Conversation (2012), proporcionam apontamentos relevantes a serem explorados na reflexão sobre o papel e a função do museu de arte universitário.

O estudo de Corrine Glesne (2012) sobre museus de arte universitários nos Estados Unidos observa que essas instituições museológicas são definidas tanto por seus administradores quanto pela comunidade acadêmica a partir de distintas metáforas: laboratório, biblioteca, joia, narrativa, portal, berçário. O significado de cada metáfora revela as potencialidades exploradas na relação entre o museu de arte universitário e sua comunidade acadêmica.

O museu de arte universitário compreendido como um laboratório serviria primordialmente à pesquisa e ao ensino da arte (Glesne, 2012).

Como um laboratório de pesquisa, os estudantes de História da Arte podem estudar obras de arte específicas ou os alunos de Educação podem observar uma visita de uma escola de ensino fundamental e como as crianças falam sobre arte. Como um laboratório de ensino, docentes de diferentes disciplinas exploram maneiras de expandir $o$ escopo de seus cursos e seus métodos de ensino por meio do uso do museu de arte. (Glesne, 2012: 6, tradução nossa)

A definição que aproxima o museu de arte universitário das funções de uma biblioteca indica que as coleções dessas instituições podem ser utilizadas para a pesquisa e produção de conhecimento e também para o lazer e prazer (Glesne, 2012). Já o museu de arte universitário visto como uma joia entende essa instituição como um equipamento especialmente atrativo ao público, acadêmico ou externo, por enfatizar que se trata de algo especial, belo e valioso - em referência ao seu valor cultural e artístico. Segundo a autora, essa é a visão mais tradicional sobre o museu de arte universitário.

A metáfora da narrativa faz referência à multiplicidade de narrativas sobre história e arte que podem ser contadas e recontadas a partir da coleção de um museu, o que o torna um elemento catalisador de discussões e reflexões interdisciplinares. A ideia de portal é utilizada no sentido 
de entender os domínios do museu de forma ampliada, para além do campus universitário, atraindo públicos e funcionando como um elo entre pessoas, recursos e ideias. E por fim, a metáfora do berçário alude à importância do museu no sentido de nutrir futuros artistas, historiadores da arte, curadores, entre outros agentes do campo.

Os participantes das entrevistas realizadas para a publicação Campus Art Museums in the 21st Century: A Conversation (2012) também ressaltaram a capacidade de atuação interdisciplinar do museu de arte universitário. Salientaram, no entanto, que essa potencialidade é dificultada pela divisão dos departamentos e as distintas metodologias e linguagens empregadas nas diferentes disciplinas ministradas, de modo que a colaboração entre as disciplinas e seus professores e o alinhamento de perspectivas muitas vezes são dificultados. Nesse sentido, Glesne (2012) observa que as universidades que pensam o ensino como colaborativo e interdisciplinar são mais propensas a apoiar e incluir o museu de arte universitário nas suas atividades acadêmicas regulares. Outro dado trazido pela pesquisa de Glesne é que o museu de arte universitário tende a ser entendido como mais relevante para a universidade, se a instituição possui uma longa trajetória e cultura de apoio às artes (Glesne, 2012).

Os participantes da publicação Campus Art Museums in the 21st Century: A Conversation (2012) identificaram como público prioritário dos museus de arte universitários os estudantes, os professores universitários e os funcionários da universidade. $\mathrm{O}$ público externo à comunidade acadêmica torna-se especialmente relevante quando o museu de arte universitário é o principal museu de arte da região (Anderson, Farrell, Linett, Shapiro, 2012). Vale ressaltar que o modo como o museu de arte universitário se relaciona com esses diferentes públicos tende a influenciar o apoio que recebe tanto da comunidade acadêmica quanto da comunidade externa.

A partir desse estudo, também é possível observar que os estudantes universitários têm buscado uma maior autonomia e um maior envolvimento em suas experiências culturais, de modo que os diretores de museus de arte universitários afirmam oferecer novas estratégias e possibilidades para que os estudantes se relacionem com essas instituições, privilegiando não apenas opções ligadas ao ensino formal, mas também atividades extracurriculares e voltadas ao entretenimento. Apesar desse dado, que demonstra uma maior proatividade e criatividade em relação ao público estudantil, a maioria dos participantes revelou que o museu de arte 
universitário ainda se encontra muito centrado em buscar o apoio e a participação sobretudo dos professores universitários, mesmo que de diferentes disciplinas (Anderson, Farrell, Linett, Shapiro, 2012).

Quanto à comunidade externa à universidade, os participantes afirmaram buscar maneiras de servir à educação formal e informal de arte também desse público. Nesse âmbito, cabe ressaltar o quanto os museus de arte universitários são identificados como espaço de pesquisa e diálogo para os artistas e comunidade criativa locais (Anderson, Farrell, Linett, Shapiro, 2012).

Partindo das reflexões de Glesne (2012) sobre o lugar que os museus de arte ocupam nas universidades e os significados que estas conferem a eles, é possível dizer que o modo como o museu é percebido por sua comunidade acadêmica e o apoio que ele recebe, seja em termos de recursos (humanos, financeiros, tecnológicos, entre outros), seja em termos de estratégias que fomentem sua visibilidade, está estreitamente relacionado à natureza de sua vinculação institucional, isto é: ao fato de o museu estar vinculado a um departamento de pesquisa, a um departamento de ensino, a um departamento de extensão ou mesmo a um departamento autônomo ou diretamente à Reitoria. Para a pesquisadora, embora o museu de arte universitário seja um espaço de ensino e aprendizado valioso para a universidade, por não estar inserido em uma lógica de "resultados acadêmicos", isto é, de publicações, produtos, etc., ele tende a receber menos investimentos e conquistar menos visibilidade (Glesne, 2012). Como ela pontua, a institucionalização do papel do museu como parte da formação universitária depende da compreensão da alfabetização visual como elemento significativo para uma boa educação (Glesne, 2012).

\section{Museus de arte universitários no Brasil e o tripé ensino, pesquisa e extensão}

Em relação ao panorama dos museus de arte universitários no Brasil, tomamos como ponto de partida o levantamento realizado por Adriana Mortara Almeida em sua tese de doutoramento, em 2001, o qual constatou a existência de 17 museus de arte universitários no país. Acrescentamos à sua investigação quatro instituições museológicas que também podem ser consideradas museus de arte universitários: a Pinacoteca Barão de Santo Ângelo - PBSA, do Instituto de Artes da UFRGS; o Museu Afro-Brasileiro da UFBA (MAFRO); o Museu 
Universitário de Arte - MunA, do Instituto de Arte da UFU/MG; e o Museu de Arte Murilo Mendes, da UFJF/MG; todos presentes no Guia dos Museus Brasileiros, elaborado pelo Instituto Brasileiro de Museus (Ibram/Ministério da Cultura), em 2011.

Assim, consideramos a existência de 21 museus de arte universitários em funcionamento no Brasil. [2] São eles, por ordem cronológica de criação junto às suas universidades: Pinacoteca Barão de Santo Ângelo - PBSA, vinculada à UFRGS (1908); Museu de Arte Sacra da Bahia da UFBA (1959); Museu de Arte da UFC/MAUC (1961); Museu de Arte Brasileira - MAB da FAAP/SP (1961); Museu de Arte Contemporânea da USP (1963); Galeria Brasiliana, vinculada a UFMG (1966); Museu de Arte Assis Chateaubriand da UEPB (1967); Coleção de Artes Visuais do IEB/USP (1968); Museu do Seridó, vinculado a UFRN (1968); Museu de Arte e de Cultura Popular da UFMT (1974); Museu da Gravura Brasileira, vinculado a URCAMP (1977); Galeria de Arte Espaço Universitário da UFES (1978); Museu de Arte Popular da UFPB (1978); Museu D. João VI, vinculado a UFRJ (1979); Museu Afro-Brasileiro da UFBA - MAFRO (1982); Museu Regional de Arte da UEFS/BA (1985); Pinacoteca da UFPB (1987); Museu de Arte Leopoldo Gotuzzo, vinculado a UFPel/RS (1996); Museu Universitário de Arte - MunA, da UFU/MG (1998); Museu de Arte Murilo Mendes, da UFJF/MG (2005) e Museu de Artes Visuais da UNICAMP - MAV/UNICAMP (2012). [3]

A maioria desses museus foi instituída com o objetivo de divulgar a arte regional, com exceção daqueles criados a partir de coleções doadas às universidades, como é o caso do Museu de Arte Brasileira da FAAP, fruto da doação de Armando Álvares Penteado; do Museu D. João VI, da Galeria Brasiliana da UFMG, do Museu de Arte Assis Chateaubriand da Universidade Estadual da Paraíba, do Museu de Arte Contemporânea da USP e do Museu Regional de Arte da Universidade Estadual de Feira de Santana, da Bahia (os quatro criados a partir do colecionismo de Assis Chateaubriand); e da Coleção de Artes Visuais do Instituto de Estudos Brasileiros da USP, constituída a partir da coleção Mário de Andrade.

De acordo com Almeida (2001), um museu ou galeria universitária constitui uma:

(...) unidade da universidade que adquire, conserva, pesquisa, comunica e expõe objetos para estudo, educação e apreciação 
(enjoyment), evidência material das pessoas e de seu ambiente, e que exibe parte ou toda a coleção em um espaço específico para isso aberto ao público em horários regulares, e pode exibir material de outras fontes de vez em quando. (Almeida, 2001: 31)

É a partir da definição utilizada pela pesquisadora que compreendemos a Pinacoteca Barão de Santo Ângelo (UFRGS), o MAFRO (UFBA), o MunA (UFU/MG) e o MAMM (UFJF/MG) como museus de arte universitários. Primeira instituição do tipo no Brasil, a Pinacoteca Barão de Santo Ângelo foi criada em 1908 junto ao então Instituto Livre de Belas Artes, com a intenção de constituir um acervo artístico para uso didático (Brites, Gomes, 2015). No decorrer dos mais de 100 anos do Instituto de Artes e especialmente a partir de sua integração definitiva à UFRGS, na década de 1960, o acervo da PBSA vem atendendo à sua função didática, sendo utilizado para projetos de ensino, pesquisa e extensão de graduação e pós-graduação. Sua apresentação no site da instituição não deixa dúvidas quanto à sua constituição enquanto museu, estando

[...] responsável pela conservação, restauração, ampliação e divulgação do patrimônio artístico e documental do Instituto, bem como pelo intercâmbio com a produção artística contemporânea. [4]

Sabe-se que os primeiros museus de arte universitários no Brasil, a exemplo da Pinacoteca Barão de Santo Ângelo, estavam associados ao ensino da arte, muitas vezes tomando as obras de suas coleções como referência e modelos de cópias. Outra experiência nesse sentido é a da coleção formada pela Academia Imperial de Belas Artes a partir da aquisição de D. João VI de 54 obras da Missão Francesa no Brasil, que foi transferida para a UFRJ e posteriormente instituída como Museu D. João VI, vinculado à Universidade. Já a coleção artística a partir da qual seria criada a Pinacoteca Barão de Santo Ângelo, começou a ser formada nos primeiros anos do século XX (1908) com o intuito de auxiliar a formação acadêmica, contendo peças como as moulages e formas de gesso, as quais recentemente foram incorporadas à Coleção Didática da Pinacoteca Barão de Santo Ângelo.

Como relata Almeida (2001), quando as primeiras coleções de arte vinculadas a uma instituição de ensino superior surgiram na Europa, nos séculos XVIII e XIX, elas eram vistas mais como 
fonte de enriquecimento cultural do campus e da vida universitária do que como suporte ou ferramenta para o ensino. O mesmo pode ser dito em relação a certos museus de arte universitários no Brasil hoje, que constituem um lugar singular de convívio para a comunidade acadêmica, intensificando as possibilidades de vivência da arte e da cultura no campus.

Como vimos, os museus universitários no Brasil surgem tanto originalmente no âmbito universitário, quanto são constituídos por coleções incorporadas pelas universidades. Apresentam, assim, diversas formas, conteúdos e estruturas organizacionais cuja principal característica em comum é a cumplicidade com o ensino, a pesquisa e a extensão (Bruno, 1997). Cumplicidade esta que está relacionada a características inerentes aos processos museais, isto é, sua vocação e comprometimento com a preservação, a sistematização e a extroversão do conhecimento produzido a partir das coleções, as quais são reconhecidamente suportes de informação.

A professora e pesquisadora Letícia Julião, coordenadora da Rede de Museus e Espaços de Ciência e Cultura da UFMG, aponta que, independente da política adotada para a preservação das coleções universitárias, "não se pode concebê-la apartada do princípio da indissociabilidade entre o ensino, a pesquisa e a extensão, que rege as universidades brasileiras" (Julião, 2015: 23). Nesse sentido, ela ressalta a necessidade de as funções específicas dos museus e da museologia - a salvaguarda e a comunicação - estarem articuladas a esse tripé da vida universitária.

Mais que reconhecer as afinidades e os pontos comuns entre essas funções, o desafio é fazê-las coincidir em um programa museológico coerente e virtuoso, tanto do ponto de vista museal quanto do acadêmico. (Julião, 2015: 23)

Já na década de 1960, o crítico de arte Mario Pedrosa (1967) sublinhava o papel fundamental de um museu de arte para a vida universitária enquanto catalisador das atividades criativas da universidade, dando suporte especialmente aos cursos de artes e comunicações. Para ele, a produção científica de um museu poderia ser considerada similar à da universidade: 
O que as distingue é que o museu dá a conhecer o resultado de suas pesquisas, expondo-as diante do público sem tardança. (...) Não conserva as suas pesquisas no círculo estreito dos especialistas, e antes as mostra ao público, para que tenham impacto imediato sobre a sensibilidade geral. (Pedrosa, 1967: 32)

A contribuição de Mario Pedrosa nos faz pensar nas particularidades de um museu de arte universitário. O que significaria atuar como catalisador das atividades criativas da universidade? E quais as possibilidades reais de um museu de arte universitário compartilhar não apenas os resultados de suas pesquisas, quase que em tempo real, mas também os próprios processos que as constituem?

Os museus universitários brasileiros, de modo geral, estão geralmente vinculados aos próprios departamentos dos quais as coleções se originaram, estando relacionados à pesquisa e ao ensino, ou, mais recentemente, estando vinculados às unidades administrativas de extensão as quais são responsáveis pelo contato da universidade com a sociedade (Ribeiro, 2013). Vale destacar, nesse sentido, a importância das universidades para os museus, pois a inserção de um acervo em uma instituição articulada pelo tripé ensino, pesquisa e extensão não deixa de contribuir para a estabilidade da instituição museológica, podendo favorecer a configuração de um adequado quadro técnico-científico, bem como ampliando suas possibilidades de financiamento.

Como destacam as pesquisadoras Roberta Smania Marques e Rêjane Maria Lira da Silva (2011), é importante, contudo, que as universidades definam com clareza o papel dos museus sob sua administração e responsabilidade, propondo políticas específicas, de maneira que essas instituições cumpram seu papel quanto ao ensino, à pesquisa e à extensão.

No que diz respeito à vocação dos museus universitários para a extensão, consideramos essa atividade um dos principais meios de valorização desses museus, por sua evidente relevância social e pela divulgação inerente a essa atividade. Para se investir nessa vocação não é necessário, contudo, afastar o museu de suas tradicionais funções vinculadas ao ensino e à pesquisa. De acordo com a professora e pesquisadora Emanuela Ribeiro (2013), tanto a extensão universitária quanto os museus universitários ainda se encontram em processo de construção dos seus mecanismos de institucionalização e legitimação no âmbito acadêmico. 
Nesse sentido, ela observa que as origens epistemológicas da atual concepção de extensão universitária se aproximam do conceito de museu proposto durante as reuniões de Santiago do Chile (1972) e Caracas (1992) (Ribeiro, 2013). Trata-se de uma concepção da extensão acadêmica enquanto ação cidadã e dialógica, sendo o museu universitário um veículo privilegiado de comunicação entre a universidade e a sociedade.

Cristina Bruno (1997), que atuou como pesquisadora e coordenadora da Divisão Cultural do Museu de Arqueologia e Etnologia da Universidade de São Paulo (MAE/USP), destaca que os museus universitários, enquanto instituições científicas financiadas pela sociedade, possuem responsabilidades culturais e sociais, de modo que a extensão é apontada como o grande potencial de difusão dessas instituições, a partir de exposições e ações educativo-culturais.

Dado que as origens das coleções universitárias estão identificadas com sua comunidade acadêmica, seus modos de vida, valores e funções sociais, é possível dizer que, independente da tipologia das coleções, o acervo de um museu universitário possui características potencialmente distintas das coleções abrigadas fora desse âmbito. Os museus universitários estão inseridos na lógica e práticas do campo científico-acadêmico, sendo tanto influenciados pela atuação de professores pesquisadores, quanto pelas regras e impedimentos da gestão pública. De acordo com Emanuela Ribeiro,

[...] o fato de ser um museu universitário é determinante para sua configuração institucional, tanto no nivel da sua missão e objetivos, quanto no nível de suas políticas de gestão institucional. (Ribeiro, 2013: 90)

Como a pesquisadora lembra, no Brasil a gestão de museus e coleções universitárias geralmente é "fruto de ações individuais de pesquisadores, ou grupos de pesquisadores, que têm particular sensibilidade para a preservação de algum acervo" (Ribeiro, 2013: 96).

Vale lembrar que a direção e administração de museus universitários são atividades que, em geral, não se traduzem em grande prestígio e capital científico no âmbito das universidades. Sendo assim, essa desvalorização institucional impacta as condições materiais e os recursos econômicos destinados aos museus universitários, de modo que tais instituições apresentam 
dificuldades de disputar recursos humanos e materiais. É por essa razão que pesquisadores como a própria Emanuela Ribeiro salientam

[...] a importância de correlacionar a gestão dos museus com o funcionamento do campo cientifico, pois são as dinâmicas internas deste campo - aliadas à gestão da coisa pública no Brasil - que atribuem o lugar dos museus nas universidades. (Ribeiro, 2013: 97)

Aqui atenta-se para uma particularidade dos museus de arte universitários: neles, a motivação para a criação e manutenção dos acervos também está vinculada à busca por outro tipo de legitimação, relacionada à distinção social que o capital simbólico cultural pode gerar no campo da arte.

Buscando organizar as contribuições até aqui expostas, percebemos que as abordagens em torno dos museus de arte universitários e sua relação com atividades ligadas ao ensino, à pesquisa e à extensão indicam que o museu de arte universitário apresenta o potencial de atuar como catalisador de discussões e reflexões interdisciplinares, salientando-se o seu papel fundamental no âmbito da extensão, para além da pesquisa e do ensino, e enquanto equipamento voltado à extroversão e ao fomento da arte e da cultura na comunidade acadêmica e externa, principalmente quando se trata do único museu de arte da região.

As considerações de pesquisadores brasileiros sobre museus universitários e sua relação com o ensino, a pesquisa e a extensão apresentam alguns pontos em comum com os estudos norteamericanos, como a insistência sobre a importância dos vínculos institucionais do museu dentro da hierarquia da universidade para sua visibilidade e fomento. A realidade dos museus universitários, em ambos contextos, aponta para a necessidade dessas instituições museológicas, desde sempre estreitamente relacionadas à pesquisa e ao ensino, cada vez mais buscarem desenvolver ações de extensão, dado o valor cultural desses museus, seja para a comunidade acadêmica, seja para a sociedade de modo mais amplo.

\section{Museus de arte universitários enquanto museus-escola e museus-laboratório}

Uma das questões suscitadas pelo presente estudo indaga se não seria da natureza do museu universitário, identificado com as ideias de um museu-escola e de museu-laboratório, repensar, 
quase que permanentemente, suas próprias funções e experimentá-las de outros modos, testálas a partir de novas ferramentas, práticas, processos, formatos, discursos. Visto que o museu pertence a uma grande escola, a universidade, não faria sentido ser ele também uma espécie de escola, tal como sugere o trabalho do artista uruguaio Luis Camnitzer? Nele, o artista inscreve na fachada de museus como o Guggenheim de Nova York (2011) e o universitário Colby College Museum of Art, de Waterville, Estados Unidos (2013), os dizeres: “O museu é uma escola. O artista aprende a se comunicar. O público aprende a fazer conexões". Vale nos perguntar: o que aprende o próprio museu?

O trabalho e o pensamento de Luis Camnitzer, para quem educação e arte não são campos diferentes, mas diferentes aspectos de uma única atividade (Camnitzer, 2009), nos reportam à chamada virada educacional na prática e no pensamento artístico e curatorial, que teve início no final dos anos 1990. Trata-se de um fenômeno que vem recuperando métodos, programas, formatos, modelos, termos, processos e procedimentos de natureza educacional para a prática e o pensamento artístico e curatorial contemporâneos. Nas palavras da curadora e pesquisadora Mônica Hoff:

Projetos de arte e curadoria passaram a operar numa espécie de práxis educacional expandida, e o mundo da arte viu nascer uma proliferação de auto-organizações e escolas geridas por artistas, bem como projetos educacionais, oficinas, palestras, seminários e fóruns qualificados como projetos artísticos, e ainda um forte incremento e investimento por parte de museus e instituições em seus programas educativos. (Hoff, 2014: 97)

Trazemos à tona o fenômeno da chamada virada educacional na arte por entender que projetos artísticos e curatoriais que tomam por base processos, ferramentas, características, discursos e contextos caros à educação podem ser de especial interesse para interpelar o modo como os museus de arte universitários vêm pensando e desenvolvendo seus programas curatoriais no que diz respeito ao tripé ensino, pesquisa e extensão, visto que se encontram em um contexto eminentemente educacional.

Outra referência que entendemos produtiva para pensar os programas curatoriais desses museus é encontrada nas experiências vinculadas ao chamado New Institutionalism. Cunhado pelo 
crítico e curador Jonas Ekeberg (2003), o termo se refere a práticas e debates críticos observados entre finais dos anos 1990 e início dos 2000, que apostam na possibilidade de transformar as instituições de arte agindo desde o seu interior, isto é, a partir de seus programas curatoriais. Isto dentro da perspectiva de inversão da relação entre crítica e instituição levada a cabo ao longo das duas últimas décadas, em que o museu deixaria de ser apenas objeto da crítica, historicamente formulada por artistas, como nas experiências já clássicas vinculadas à chamada crítica institucional, para passar a anunciá-la, num esforço de autorreflexão.

De fato, entre meados dos anos 1990 e meados dos 2000 observou-se, sobretudo em instituições públicas europeias de médio porte - tais como Bergen Kunsthall, em Bergen, na Noruega; Rooseum, em Malmö, na Suécia; e Palais de Tokyo, em Paris - um investimento em discursos e práticas curatoriais que colocavam em questão o papel e a função dessas mesmas instituições, experimentando outras possibilidades de atuação e de engajamento com a arte, com os artistas, com o contexto institucional e comunitário e com seus públicos.

Maria Lind, uma das curadoras frequentemente associadas ao chamado New Institutionalism, ressalta que uma de suas principais intenções ao desenvolver o programa do Kunstverein München, que dirigiu entre 2002 e 2004, era seguir as direções apontadas pelas práticas artísticas para pensar como uma instituição poderia ser mais sensível à arte, isto é, estar a serviço dos artistas e produzir um diálogo interessante com eles (Lind, 2013: 30). A proposta de trabalhar a partir de uma sensibilidade em relação à produção artística informa outras experiências da curadora, a exemplo do programa desenvolvido para o Moderna Museet de Estocolmo, entre 1998 e 2001, cujas atividades nem sempre se traduziam em exposições propriamente ditas, como explica a curadora:

Uma instituição ainda é pensada primordialmente como um showroom, e exposições são tomadas como o modo natural de lidar com arte. $\mathrm{Na}$ realidade, uma exposição é somente uma maneira dentre tantas outras de trabalhar com arte e fazê-la existir. Assim como muitos artistas utilizam o meio e a técnica relevantes para a pergunta que eles fazem a si mesmos, temos de nos perguntar que formato é relevante para o que o artista e nós queremos fazer. (Lind, 2000: 88, tradução nossa) 
Intitulado Moderna Museet Projekt, o programa criado por Lind comissionava propostas artísticas sensíveis ao contexto do museu, mas não necessariamente específicas para aquele lugar: context-sensitive e não site-specific, como explica a curadora (Lind, 2000: 94). A instituição deveria funcionar, portanto, como plataforma de produção e distribuição da arte, e não apenas de exibição e mediação. Buscando responder às especificidades e necessidades de cada trabalho, a ideia era que eles não fossem obrigatoriamente apresentados dentro do museu, mas no lugar e do modo que sua natureza determinasse, seja em um espaço temporário de exposição, nas ruas, nas páginas de uma revista ou mesmo em locais tradicionalmente não utilizados dentro da instituição.

A proposta exemplifica o que Claire Bishop também identifica como

uma tendência visível entre centros de arte: reconceitualizar o modelo 'cubo branco' de exibição de arte contemporânea, substituindo-o pelo modelo 'estúdio' ou 'laboratório' experimental'. (Bishop, 2011: 109)

Segundo ela, curadores como Maria Lind, Hans Ulrich Obrist e Nicolas Bourriaud teriam adotado esse modus operandi curatorial em reação ao tipo de arte produzida nos anos 1990: “trabalhos abertos, interativos, resistentes ao fechamento, frequentemente parecendo estar 'em andamento', ao invés de objetos concluídos” (Bishop, 2011: 110).

Tratava-se de reconceitualizar não só o modelo "cubo branco", mas a instituição e suas tradicionais funções de modo mais amplo, entendendo-a não apenas como espaço de conservação, exibição e mediação, em que os diferentes públicos eram chamados a participar, sobretudo por meio da observação e da contemplação, mas como espaço de ação, debate, participação, produção e transformação.

Como propõe o curador Charles Esche, também associado ao New Institutionalism, o tipo de instituição capaz de promover uma produção voltada à experimentação, ao questionamento e à descoberta tem de funcionar em parte como centro comunitário, em parte como laboratório e em parte como a academia, sendo menos necessária a tradicional função expositiva (Doherty, 2004: 2). 
Pois a problematização do próprio museu e de suas tradicionais funções - colecionar, conservar, estudar, interpretar e expor -, bem como o questionamento do modo como o museu se relaciona com a própria arte, os artistas, seus contextos e seus públicos, ainda que nos falem de um cenário absolutamente distinto, pelo contexto em que o New Institutionalism se desenvolve, nos parecem especialmente valiosos para interpelar e indagar os museus de arte universitários hoje. Seja em relação à vocação desses equipamentos para o ensino, a pesquisa e a extensão, seja em relação ao modo como essa vocação se articula e se desenvolve por meio de seus programas e projetos curatoriais. Ou mesmo em relação à abertura que tais instituições, a nosso ver, podem ter no sentido de se constituírem como museus autorreflexivos, abertos a indagar suas próprias funções e experimentá-las de outros modos, testá-las, como apontamos antes, a partir de novas ferramentas, práticas, processos, formatos e discursos. Sendo tais museus pertencentes a instituições de ensino e pesquisa por natureza, parece-nos que uma de suas potencialidades está em justamente reconhecerem-se, eles também, enquanto museus-escola e museus-laboratório, voltados à produção e ao compartilhamento de conhecimentos e saberes por meio da preservação, pesquisa e comunicação de suas coleções.

Retomando a questão se os museus de arte universitários seriam diferentes de outros museus e em que aspectos, a discussão promovida por teóricos e diretores de museus americanos sugere que sim: pela capacidade de serem mais experimentais e inovadores e por apresentarem estruturas mais ágeis e menos burocráticas. Aqui, trazemos a experiência do Museo Experimental El Eco, vinculado à Universidad Nacional Autónoma de México (UNAM) e localizado na Cidade do México. Por apresentar uma estrutura física e uma equipe bastante reduzidas, além de uma programação relativamente enxuta e um funcionamento flexível, o museu parece se tornar mais poroso às reflexões trazidas pelos artistas que ali trabalham. Em primeiro lugar, estes mantém contato com toda a equipe do museu ao realizar comissionamentos, sendo que todos os funcionários parecem se engajar, de uma maneira ou de outra, no desenvolvimento de cada trabalho. Em segundo lugar, a ideia é que os projetos artísticos e os questionamentos por eles trazidos alimentem a programação que se vai estabelecendo para o museu, ou seja: há uma abertura para as perguntas que as propostas artísticas colocam à instituição e um desejo mesmo de que estas possam constituir um campo de reflexão em seu interior. Caso dos projetos comissionados anualmente para o pátio da instituição por meio do programa Pabellón Eco, a exemplo da intervenção com blocos de 
concreto proposta pela arquiteta Frida Escobedo, em 2010, que acabou por criar uma arquitetura efềmera disponível para encontros, conversas e outras atividades propostas pelos públicos e pelo próprio museu. É quase como se este fosse o propósito final dos comissionamentos realizados pelo El Eco, muitos deles voltados às especificidades do lugar: que eles possam retornar à instituição enquanto perguntas, torções, questionamentos, propostas, isto é, que possam alimentar o modo como o museu é conduzido.

Nesse sentido, talvez seja possível entender que a porosidade de uma instituição ao fazer e ao pensar artísticos, isto é, sua capacidade de se remodelar a partir dos trabalhos, práticas e indagações trazidos pelos artistas - e quem sabe também, pelos públicos -, talvez seja inversamente proporcional à sua escala, justamente pelo dado de engessamento e falta de flexibilidade que uma escala institucional maior costuma significar. Daí a possibilidade de pensar que uma das potencialidades dos museus de arte universitários está ligada às suas estruturas, geralmente mais enxutas e portanto mais flexíveis e mais aptas a se reinventar.

Para finalizar, ao levarmos em conta a realidade brasileira e indagarmos sobre a capacidade de nossos museus de arte universitários estruturarem-se de modo mais ágil e menos burocrático, como sugere a avaliação americana, dificilmente poderemos afirmar o mesmo - pelo menos não da mesma forma. Não necessariamente pelo fator burocracia, mas pela escassez de recursos que costuma caracterizar as instituições desse tipo no país, o que fatalmente limita sua capacidade de ação. Entretanto, em relação à possibilidade de tais museus atuarem de modo mais experimental e inovador, acreditamos que a liberdade acadêmica pode, sim, permitir uma maior ousadia e experimentalismo por parte de seus programas curatoriais. Se tomarmos que uma das importantes funções dos museus de arte universitários é encorajar práticas de pesquisa e de ensino inovadoras, especialmente nos campos da arte, museologia, história, crítica e curadoria, correr riscos pode ser valorizado e aquilo que poderia ser tomado como "erro" pode ser percebido como um resultado a ser observado, analisado, estudado, criticado e reinventado, de modo a alimentar novas práticas e reflexões. As métricas de sucesso aqui podem mais facilmente ser outras, não tão ancoradas em resultados - número de pesquisas, exposições, publicações, visitantes, etc. -, mas em processos e aberturas a outros caminhos. 
[1] Este artigo integra a pesquisa Museus de arte universitários e seus programas curatoriais: ensino, pesquisa e extensão, sob a coordenação da Profa. Dra. Fernanda Carvalho de Albuquerque, em desenvolvimento junto ao Departamento de Ciência da Informação da FABICO/UFRGS (2016-2020). A pesquisa investiga como tais instituições museais atuam enquanto plataformas de ensino, pesquisa e extensão no âmbito de suas universidades, por meio de sua ação curatorial. A etapa seguinte da pesquisa, dedica-se, portanto, a indagar como determinados programas ou projetos curatoriais desenvolvidos por instituições tais como a Pinacoteca Barão de Santo Ângelo, vinculada ao Instituto de Artes da UFRGS, e o Museo Experimental El Eco, integrante da Universidad Nacional Autónoma de México (UNAM), respondem e articulam a vocação do museu de arte universitário para atuar com pesquisa, ensino e extensão.

[2] Disponível em: http://www.museus.gov.br/guia-dos-museus-brasileiros/ (acesso em janeiro de 2019).

[3] Vale observar que a Galeria de Arte da UNICAMP, fundada em 1984, teve seu acervo incorporado ao Museu de Artes Visuais da UNICAMP (MAV/UNICAMP), criado oficialmente em 2012.

[4] Disponível em http://www.ufrgs.br/artes/espacos-culturais/pinacoteca-barao-de-santo-angelo (acesso em 10/02/2016).

\section{Bibliografia}

ALBUQUERQUE, Fernanda Carvalho de. Práticas artísticas orientadas ao contexto e crítica em âmbito institucional. Tese de doutoramento apresentada ao Programa de PósGraduação em Artes Visuais do Instituto de Artes da UFRGS. Porto Alegre: Universidade Federal do Rio Grande do Sul, 2015.

ALBUQUERQUE E MOURA, Allana Barcelos de. Públicos espontâneos no museu de arte universitário - Um estudo sobre a relação dialógica em uma exposição. Dissertação de Mestrado apresentada à Faculdade de Artes, Filosofia e Ciências Sociais da Universidade Federal de Uberlândia. Uberlândia/Minas Gerais: Universidade Federal de Uberlândia, 2012.

ALMEIDA, Adriana Mortara. Museus e coleções universitários: por que museus de arte na Universidade de São Paulo?. Tese de doutoramento apresentada à Escola de Comunicações e Artes da Universidade de São Paulo. São Paulo: Universidade de São Paulo, 2001.

ANDERSON, Will; FARRELL, Betty; LINETT, Peter; SHAPIRO, Tom. Campus Art Museums in the 21st Century: A Conversation, 2012. Disponível em: https://culturalpolicy.uchicago.edu/campus-art-museums-21st-century-conversation.

Acesso em 14 de agosto de 2016. 
BISHOP, Claire. Antagonismo e estética relacional. In: Tatuí, vol. 12. Recife, 2011.

BISHOP, Claire. Radical Museology. Or, What's 'Contemporary' in Museums of Contemporary Art? Londres: Dan Perjovschi and Koenig Books, 2013.

BRITES, Blanca; GOMES, Paulo. A Pinacoteca Barão de Santo Ângelo. In: GOMES, Paulo (org.). Pinacoteca Barão de Santo Angelo: Catálogo geral - 1910-2014. Porto Alegre: Editora da UFRGS, 2015.

BRUNO, Cristina. A indissolubilidade da pesquisa, ensino e extensão nos museus universitários. In: Cadernos de Sociomuseologia, [S.1.], v. 10, n. 10, junho 2009.

CAMNITZER, Luis; PÉREZ-BARREIRO, Gabriel. Educação para a arte / Arte para a educação. Porto Alegre: Fundação Bienal, 2009.

COLEMAN, L. V. College and University Museums: a Message for College and University Presidents, AAM, Washington DC, 1942.

COUTO, Maria de Fátima Morethy. O Museu de Artes Visuais da UNICAMP: sua coleção e seus objetivos. In: Revista Museologia \& Interdisciplinaridade. v.1, $\mathrm{n}^{\mathrm{o}}$ 5, maio/junho de 2014, p. 223-231.

DOHERTY, Claire. From Studio to Situation. Londres: Black Dog Publishing, 2004.

EKEBERG, Jonas (ed.). New Institutionalism. Oslo: Office for Contemporary Art Norway, 2003.

GLESNE, Corrine. IV Challenges and Conditions of Succes for Campus Art Museums. In: The Campus Art Museum: a qualitative study. 2012, p. 4-26.

GOMES, Paulo (org.). Pinacoteca Barão de Santo Ângelo: Catálogo geral - 1910-2014. Porto Alegre: Editora da UFRGS, 2015.

GOMES, Paulo. A Coleção Didática da Pinacoteca Barão de Santo Ângelo. In: GOMES, Paulo (org.). Pinacoteca Barão de Santo Ângelo: Catálogo geral - 1910-2014. Porto Alegre: Editora da UFRGS, 2015. p. 39-48.

GUIA DOS MUSEUS BRASILEIROS. Disponível em: http://www.museus.gov.br/guia-dosmuseus-brasileiros/.

GUTHE, Alfred. The Role of a University Museum. In: Curator, 9(2), 1966.

HOFF, Mônica. A virada educacional nas práticas artísticas e curatoriais contemporâneas e o contexto de arte brasileiro. Dissertação de mestrado. Porto Alegre: Programa de PósGraduação em Artes Visuais da UFRGS, 2014. 
KOLB, Lucie et FLÜCKIGER, Gabriel (eds.). (New) Institution(alism) - oncurating.org, n. 21. Zurique: oncurating.org, dezembro de 2013.

LIND, Maria. Learning From Art and Artists. In: WADE, Gave (org.). Curating in the $21^{\text {st }}$ Century. London: University of Wolverhampton, 2000.

LIND, Maria. "We want to become an institution" - An Interview with Maria Lind. In: KOLB, Lucie et FLÜCKIGER, Gabriel (eds.). (New) Institution(alism) - oncurating.org, n. 21. Zurique: oncurating.org, dezembro de 2013.

MENESES, Ulpiano T. Bezerra. O museu e a questão do conhecimento. In: GUIMARÃES, Manoel Luiz Salgado; RAMOS, Francisco Régis Lopes (orgs.). Futuro do pretérito Escrita da história e história do museu. Fortaleza: Instituto Frei Tito de Alencar, 2010.

O’NEILL, Paul; WILSON, Mick (orgs.). Curating and the Educational Turn. Londres: Open Editions; Amsterdã: De Appel, 2010.

PEDROSA, Mario. A função do museu no core universitário. In: Revista GAM: Galeria de Arte Moderna, no 3, fevereiro 1967.

POULOT, Dominique. Museu e Museologia. Belo Horizonte: Autêntica Editora, 2013.

RIBEIRO, Emanuela Souza. Museus em Universidades Públicas: entre o campo científico, o ensino, a pesquisa e a extensão. In: Museologia \& Interdisciplinaridade. Vol. II, $\mathrm{n}^{\mathrm{o}} 4$, maio/junho de 2013, p. 88-102.

SMANIA MARQUES, Roberta; DA SILVA, Rêjane Maria Lira. O reflexo das políticas universitárias na imagem dos museus universitários: o caso dos museus da UFBA. In: Revista Museologia e Patrimônio. vol. 4, n. 1, 2011: p. 63-84. 